\title{
Video Conferencing and Knowledge Management in In-Service Teacher Distance Lifelong Training and Development
}

\author{
Anna Kamakari and Athanasios Drigas \\ NCSR 'Demokritos', \\ Institute of Informatics and Telecommunications, \\ Net Media Lab, \\ Agia Paraskevi, 153 10, Athens, Greece \\ anora@otenet.gr, dr@iit.demokritos.gr
}

\begin{abstract}
In Greece, the training system and education can be adapted to distance lifelong e-learning and the teachers, the society and the economy can be benefited via the introduction and training of in-service teachers in a) the Video Conferencing (VC) technology and mode of distant training, granted that VC is put into a learning framework, and b) Knowledge Management (KM) methodology, through lectures and seminars. Incidentally, VC technology and KM methodology can be integrated into in-service teacher distance lifelong training and development, and to this end, an example, a hybrid model, of the manner $\mathrm{VC}$ technology and KM methodology can be integrated into in-service teacher distance lifelong training and development, that is, a microteaching session via $\mathrm{VC}$ and $\mathrm{KM}$, which is advisable for Greek teachers of all specialisations in Greece or abroad, is given.
\end{abstract}

Keywords: Video conferencing, knowledge management, distance lifelong inservice training, managed learning environment, microteaching.

\section{Introduction}

Distance learning is associated with distance education, while interactive distance learning systems are a highly valuable tool in the delivery of education and training to widely dispersed trainees, and in cases where the trainer cannot travel to the trainee's site in accordance with the European Commission's [1] policy on e-learning, which gives priority to those who live in remote areas or the disadvantaged, since distance education offers opportunities in situations where traditional education has difficulty to operate. E-learning is suited to distance learning, flexible learning, and blended learning and is associated with advanced learning technology, while in higher education, a virtual learning environment - sometimes combined with a Management Information System (MIS) to create a Managed Learning Environment - is used [2]. MISs are used a) to analyse other information systems which are applied in operational activities in an organisation, and b) to automate or support human decision making [3]. 
In this paper, focus will be on distance lifelong training for in-service teacher development on and via video conferencing and knowledge management. Desktop video conferencing, on the one hand, links geographically dispersed groups or individuals using powerful Computer-Mediated Communication technology, which learners perceive as a motivating factor, appeals to different learning styles, and makes learning fun [4]. Knowledge management, on the other hand, is the management of an organisation with a special focus on knowledge [5]. Firstly, according to connectivism, learning is defined as actionable knowledge, resides within an organisation or a database, connects specialised information sets, and the connections which enable people to learn are more important than their current state of knowing [6]. Secondly, connectionists challenge Chomsky's cognitivism and hold that learning and cognition are associated with the manner neurons interconnect and communicate in the brain; construct artificial and highly simplified networks of neurons which exist as computer simulations and are a minute fraction of the size of the real brain, to mimic the behaviour of the brain; and have proved that a network can be trained to perform any mapping operation [7], that is, to discover, for instance, what knowledge exists at the beginning of a KM project (:knowledge audit) [8].

The paper is organised as follows: Section 2 presents VC in relation to computersupported collaborative software, the European as well as the Greek Research and Education Network, and the Greek Schools Network. Section 3 presents a premise associated with the manner VC and KM can be integrated into in-service teacher training and development so that the training system and education can be adapted to distance lifelong e-learning, and the intrinsic operation of the school units can be improved since past knowledge will be integrated and new knowledge will be created. Section 4 presents an analysis of the impact of VC and KM on the teachers, the society, and the economy. Section 5 presents the following steps that are being pursued in this research, and finally, section 6 presents the conclusions of the work presented in this paper.

\section{Video Conferencing}

Video conferencing serves groups in two or more locations who interact simultaneously via two-way video and audio transmissions with the use of electronic transmitters, such as computers over Internet telephony (VoIP). In e-learning, seminars are transmitted via webcasting, which is broadcasting over the Internet, and in which a content source is taken and distributed - live or recorded - to many simultaneous listeners or viewers by streaming media technology. Video conferencing is supported by the European Research and Education Network, GÉANT2, as well as the Greek Research and Education Network (Ethniko Diktuo Ereunas kai Technologias - EDET). Collaborative software related with computer-supported cooperative work as well as research and education networks in Europe and in Greece will be presented in short.

\subsection{Collaborative Software}

Collaborative software can be either web-based or desktop systems, while electronic communication tools, electronic conferencing tools and collaborative management 
(co-ordination) tools constitute the three categories of collaboration groupware [22]. Electronic communication tools include synchronous conferencing, Web publishing, wikis, faxing, e-mail, voicemail, and revision control, while electronic conferencing tools include telephony, video conferencing over VoIP, instant messaging, application sharing such as desktop sharing or screen sharing, data conferencing or electronic whiteboard with annotation, online chat as well as Internet forums for virtual discussion, and Electronic Meeting System Tools [9] which facilitate group decisionmaking such as electronic brainstorming and rank order vote among others. Additionally, slide presentations created via Power Point, live video, as well as polls and surveys with multiple-choice answers [10]. Collaborative management tools, finally, include electronic calendars, project management systems, workflow systems related to collaborative management of information, knowledge management systems which collect, manage, organise, and share forms of information, prediction markets, extranet systems and hosted intranet systems where the information is associated with the delivery of a project, social software systems which organise social relations of groups, and online spreadsheets which are related to collaborative and shared structured data and information [9].

\subsection{Research and Education Networks in Europe and in Greece}

A National Research and Education Network (NREN) is a specialised Internet service provider that supports research and educational communities within a country by providing the infrastructure -- for instance, virtual collaborations, teleteaching, school networks -- which is fundamental in order for education to respond to the rapid developments and to stay competitive and attractive to Europeans and non-Europeans [11], and all aspects of research and education networking to be developed by different types of users. GÉANT2, the backbone network of the European NRENs, interconnects Europe's national research and education networks, while it is connected to research networks and academic backbones worldwide so as international collaboration and development to take place in the frame of the European strategic objectives of education. The non-profit association of the European NRENs is called TERENA, an acronym of Trans-European Research and Education Networking Association. TERENA supports the European research and education community via the promotion and development of high-quality international information and telecommunications infrastructure [12].

GRNET is the non-profit Greek National Research and Education Network which is interconnected at the Pan-European network GÉANT2. GRNET2 is the generation of advanced technology at extra high speeds [13], while GRNET3 supports e-science applications and Internet Usage [14] at a Pan-Hellenic level. GRNET offers among others, the following services to researchers, professors and students of Universities and of Technological Education Institutes: newsgroups and news feeds, diodos that offers permanent ADSL connection from residence at the minimum charge as long as the academic studies last, real-time multipoint video conferencing sessions and teleteaching activities, IP telephony service which allows the communication of data across the Internet, webcasting, and video on demand.

Along with the Greek Universities Network (GUnet), GRNET supports the Greek Schools Network (GSN or SCH.gr) providing it with Internet Services. The GSN 
offers the following services to its basic and middle education units and users: a) the WWW portal which offers among other telematics services, Web mail access, calendar, notes agenda, task list, discussion forums, collaboration environment for asynchronous e-learning, and news services which distribute informative material related to the GSN registered users who are allowed to post news and announcements; b) the users administration service which provides the users with remote network access (dial-up), Web space of their own Web pages, and e-mail service; c) instant messaging integrated with teleconferencing where a web interconnection permits the user to select day, month and week views; d) asynchronous e-learning platform; e) video on demand; and f) the users support service (Helpdesk) which provides telematics services and solutions to connection problems as well as technical aid to the users by phone or with ad loc visit.

\section{State of the Art}

Video conferencing meets the needs and demands of the Greek teachers and is in conformity with the aim and the goals of in-service teacher training as well as the goals set out by the Lisbon European Council and the concrete strategic objectives of education and training systems adopted by the Education Council. As concerns the needs and demands of the Greek teachers, research [15], [16], [17], [18] conducted in Greece has shown that teachers of both primary and secondary education engage in critical reflection on their experiences in order to change their meaning schemes, a fact that according to Mezirow [19] leads to perspective transformation which leads to transformative learning. Granted that 76,000 Greek in-service teachers of all specialisations have already been trained in the use of ICT in education [17], in order for transformative learning to be realised, lectures and seminars on and via video conferencing and knowledge management should take place.

\subsection{ICT Induced Training for Professional Development}

Research a) conducted in Greece and related to the needs and demands of the Greek teachers has shown that teachers of the Primary and the Secondary Education carry a positive feeling towards the use of ICT in education [15], [16], [17], [18], are aware of distance education and favour it when contrasted with face-to-face education [18], and desire to attend training programmes related to the use of ICT [16], while b) research conducted abroad has shown a) that the quality of online education equals or is better than traditional education [20], b) that students prefer the electronic classroom at a local site [21], and c) that in the field of microteaching, the use of videotape recordings is an effective method of teacher training [22]. Moreover, Vassala and Motsios [18] characterise conventional training as not flexible, while Papadakis and Fragoulis as well as Papadouris [18] state that distance education could be implemented in introductory training and in other training environments.

Therefore, as regards distance lifelong in-service teacher training and development, video conferencing along with knowledge management meets the needs and demands of the Greek teachers and is in accordance with a) the aim of in-service teacher training, which is to supplement and integrate their knowledge substructure in order to make it practically beneficial as well as the goals of in-service teacher training which 
are related to their personal and professional development and the effectiveness of the educational system within which they work [23]; and b) the goals set out by the Lisbon European Council and the concrete strategic objectives of education and training systems adopted by the Education Council [11], granted that firstly, it aims at the development of the adult throughout his professional life and aids teachers to get a real advantage from multimedia resources and interactive possibilities, secondly, it facilitates the access of all to education and training systems through collaborative software as well as the GSN which is supported by the GRNET and the GUnet, and incidentally, the skills of the labour force correspond to the technological and economic evolution.

\subsection{VC and KM in In-Service Teacher Distance Lifelong Training and Development}

In order for transformative learning to be realised, lectures and seminars on and via video conferencing (VC) and knowledge management (KM) grounded on the following learning theories should take place: a) constructivism related to distance learning and supported by VC, since it offers flexibility to teachers who use technology tools to augment cognitive and metacognitive processes [24], and b) connectivism associated with rationalism - since tacit and explicit knowledge is expected to be available throughout the school unit - as well as connectionism related to artificial neural networks and KM activities driven by KM needs and supported by ICTs, artificial intelligence and needs analysis techniques.

Firstly, lectures and seminars on VC and KM should be based on the aim and the goals of in-service teacher training and could be organised at national level by the Ministry of Education, the Pedagogical Institute, and Bodies and Services (such as the Adult Education General Secretariat and Computer Technology Institutes) which aim at the promotion and diffusion of lifelong learning, while experts should be assigned in order to incorporate technology into learning environments. Furthermore, support could be provided by a) training institutions and scientific unions of adult education and distance learning as well as b) GRNET which works in partnership with the European NRENs and supports GUnet and GSN, and c) European universities and the European Union.

Secondly, in the frame of seminars via VC and KM,

a microteaching (that is, a minute lesson which a) consists of self-study, evaluation and peer supervision, and b) is a valuable training method that increases training effectiveness, granted that the foundations of its protocol are immediate, focused feedback and encouragement as well as the opportunity to practice the suggested improvements in the same training session so that the trainees improve both methods and content of teaching, and develop specific teaching skills [25]),

$\checkmark$ real-time nation-wide or world-wide broadcast link (which connects two or more nodes)

$\checkmark \quad$ video conferencing flexible blended learning distance lifelong in-service teacher training and development session

$\checkmark$ accompanied by control access activities and interactive data conferencing, constitutes a hybrid model so as best use of the literature and technology discussed to be made. 
Assessing KM activities last $10^{\prime}-15^{\prime}$ and indicate according to Bornemman et al. [5] a) the knowledge available before microteaching, -- through constructive electronic portfolios [24] -- granted that focus is not on the actual process of learning, but on the value of what is being learned and on the meta-skill of evaluating the worthiness of learning something before learning itself begins [6] according to connectivism, b) how it has been developed over time and c) the extend to which non-explicit knowledge goals have been reached. Connectionist knowledge mapping and connectivist assessment is related to self-improvement (external), while evaluation of the training centre's goals is related to accountability (internal) and is in conformity with KM methodology.

In KM planning and organisation activities, teachers of the same specialisation from Greece or abroad, select the time, the location, the place, and the duration of the session according to their needs and demands, with the help of collaborative management tools and via the collaboration platform of the GSN, in collaboration with the executives of education, the assigned experts, and the training centres. Two groups of teachers, which consist of four or five peers each, constitute the participants. Three or four of the peers from both groups assume the role of the teacher and schedule the lessons, and with the students-trainees of both groups form one self-study group and have three or four complete microteaching cycles of ten to fifteen minutes each, so as VC to operate in relatively short, interactive sessions, in line with the theory [26].

Both groups interact from the same location each, being at a VC room at a school, or at a training centre of the public sector, or at the nearest university campus, or at a mobile VC studio. One of the two groups, nevertheless, can attend the VC session and interact from different locations of the country or from abroad with the four or five peers being at their home each without having the possibility to teach, but only to play the student role, since blended learning is used. At the same time, another microteaching session via VC takes place with similar audiences.

In microteaching, each new skill is introduced to trainees in varied combinations of face-to-face training sessions, printed materials, and multimedia presentations [25], and therefore, $\mathrm{VC}$ technology is treated as one component of a multi-mode approach to delivery [26]. In KM creation and transfer activities, online training materials, information, and general presentations can be created with Adobe Flash multimedia technologies which add animation, interactivity and video to web pages, while a document camera transmits images of documents, slides or overhead projectors to remote sites. An electronic whiteboard with animation allows the presenter, the attendees, or both, to make notes on a blank whiteboard, or to mark or highlight items on a slide presentation. Other VC tools are web browser spreadsheets, slide presentations created via Power Point, live video through a digital video camera or webcam, and recording for viewing at a later time be anybody who uses a unique web address [10], while group decision-making is facilitated by electronic meeting system tools, which are idea generation techniques. Accordingly, VC facilitates conventional learning with face-to-face meetings, and distance learning with more class materials and better preparation of teaching materials [21].

There follow KM creation, transfer, integration and maintenance activities. The teachers watch and comment on the single-concept microteaching lesson, while a) 
peer evaluation of the teaching episode is provided by each of the teachers who play a student role and consists of -- one or -- two compliments and -- one or -- two suggestions related to the specific skill being emphasised or to other aspects of the lesson; $b$ ) trainees feel empowered by the compliments and suggestions of the peers and trained supervisors -- or assigned experts - chairmen, when present, in the frame of constructivism -- ; c) the teachers who have taught the lessons, have a brief time to use the feedback they have received to replan and reteach the same lessons to another group immediately [25], since at the same time, another microteaching session via VC takes place with different audiences so as feedback on the retaught lessons to be given by another audience.

Feedback is aided by playing back the video recordings [25], since research has shown that the use of videotape recordings is an effective method of teacher training [22]. Eventually, the video material of the broadcast, that is, the session, is uploaded to the GSN's Video on Demand server and is retrieved by the end-users later. After the session has ended, the teachers can be in contact whenever they select to be, via the GRNET's news service which provides message exchange in discussion lists and article exchange to all its partners. Apparently, the intrinsic operation of the school units will be improved, since rationalist and cognitivist tacit (cf. Chomsky's competence) and explicit (cf. Chomsky's performance) knowledge will be made available throughout the school units in which the teachers work.

\section{Impact of VC and KM on the Teachers, the Society, and the Economy}

The rationale of the paper resonates with the aim and the goals of in-service teacher training and development as well as the goals set out by the Lisbon European Council and the concrete strategic objectives of education and training systems adopted by the Education Council [11].

In Greece, the training system and education can be adapted to distance lifelong elearning and the teachers, the society and the economy can be benefited, granted that $\mathrm{VC}$ along with $\mathrm{KM}$ a) reduces the inequalities among the trainees and constitutes an effective means of communication, cooperation, interaction, development, and active citizenship for a wide range of trainees around the country; b) contributes to the development of the school units' and training centres' core competences and core performance capabilities with improved or faster learning and new knowledge creation; c) offers a competitive advantage within the national and the European educational system as well as the economy, since firstly, the skills of the teachers correspond to the technological and economic evolution, and secondly, innovation stakeholders are encouraged to contribute to the creation of innovative educational training environments; and d) strengthens cooperation among European and non-European Unit countries in the field of education and training systems via GÉANT2 and TERENA, and thus, European education and training systems become competitive, and in consequence, attractive to Europeans and non-Europeans. 


\section{Future Research}

Granted that video conferencing will be universally accepted as the next mode of communication [21], as research conducted abroad and in Greece implies, further research could focus on preservice teacher training, on the training of the executives of education and of post-secondary education students and teachers on and via VC and $\mathrm{KM}$ as well as on KM as regards school unit or Academic Institution management. Furthermore, since societies in which adult education and training are seen as separate from compulsory schooling, are always going to be of marginal concern [27], decision makers, at all levels, should be supported to address education policy issues, such as innovation, European and international collaboration, and integration of new learners [28] so as high-quality, selected and up-to-date education developments to take place -- in Greece and -- throughout the Community [29].

\section{Conclusion}

VC has been put into a learning framework and a premise associated with the integration of $\mathrm{VC}$ and $\mathrm{KM}$ into in-service teacher distance lifelong training and development has been put forward. Both axes of the premise, that is, a) the introduction and training of in-service teachers in the Video Conferencing technology and mode of distance training and in Knowledge Management methodology through lectures and seminars as well as b) an example, a hybrid model, of the manner VC technology and KM methodology can be integrated into in-service teacher distance lifelong training and development, that is, a microteaching session via $\mathrm{VC}$ and $\mathrm{KM}$, which is advisable for Greek teachers of all specialisations in Greece or abroad, make up solid foundations for in-service teacher distance lifelong training and development, meet the needs of the teachers, the society and the economy, and are in line with the aim and the goals of in-service teacher training and development as well as the European Education Council's [11] strategy as regards education and training systems in Europe.

\section{References}

1. European Commission Directorate-General for Education and Culture. ICT@Europe.edu: Information and Communication Technology in European Education Systems (2001), http: / /www. eurydice.org/ressources / eurydice/pdf / 0_integral/0 $20 E N$.pdf (retrieved February 5, 2008)

2. Electronic Learning (2008), http://en.wikipedia.org/wiki/Electronic_classroom (retrieved January 19, 2008)

3. Management Information System (2008), http://en.wikipedia.org/wiki/Management_Information_Systems (retrieved March 23, 2008)

4. Firestone, J.: Desktop videoconferencing: investigating the organisation of turn-taking strategies for effective communication in language learning (1999), http://www.geocities.com/jefirestone/master.html (retrieved July 31, 2005) 
5. Bornemann, M., Graggober, M., Hartlieb, E., Humpl, B., Koronakis, P., Primus, A., et al.: An Illustrated Guide to Knowledge Management (2003), http: / /www.wmforum.org/files/Handbuch/An_Illustrated_Guide _to_Knowledge_Management.pdf (retrieved August 17, 2007)

6. Siemens, G.: Connectivism: A Learning Theory for the Digital Age (2004), http: / / www. elearnspace.org/Articles/connectivism.htm (retrieved March 31, 2008)

7. Shanks, D.: Braking Chomsky's rules: Computers with a talent for grammar and syntax are challenging the theory at the heart of modern linguistics. If they can learn by trial and error, why should humans rely on rules? New Scientist magazine 1858(26) (January 1993), http: / /www. newscientist.com/article.ns?id=mg13718584.800\&pri $\mathrm{nt}=$ true (retrieved March 14, 2008)

8. Knowledge Management (2008), http://en.wikipedia.org/wiki/Knowledge_management (retrieved March 13, 2008)

9. Collaborative Software (2008), http://en.wikipedia.org/wiki/Collaborative_software (retrieved January 26, 2008)

10. Web Conferencing (2008), http: / / en.wikipedia.org/wiki/Web_conferencing (retrieved January 30, 2008)

11. Education Council of the European Union. Report from the Education Council to the European Council, The concrete future objectives of education and training systems (2001), European Commission Web site, http://ec.europa.eu/education/ policies/2010/doc/rep_fut_obj_en.pdf (retrieved April 24, 2008)

12. TERENA Statutes (2006), http://www.terena.org/about/statutes.html (retrieved July 21, 2008)

13. Network Description / Map (2007), http: / / www.grnet.gr/default.asp?pid=27\&1a=2 (retrieved February 2, 2008)

14. Development (2007), http://www.grnet.gr/default.asp?pid=28\&1a=2 (retrieved February 2, 2008)

15. Mpalwmenou, A.: Antilhpseis Ekpaideutikwn gia thn Epimorfwsh sthn Aksiopoihsh twn Texnologiwn Plhroforias kai Epikoinwniwn: Anagkes -Kinhtra. $2^{\circ}$ Ekpaideutiko Synedrio Epimorfwsh twn Ekpaideutikwn: adynamies, dynatothtes, prooptikes. Kozanh: Tomeas Episthmonikhs Kathodhghshs B/athmias Ekpaideushs Perifereiakhs D/nshs Ekp/shs D. Makaidonias (2005)

16. Papadanihl, I.: H Epimorfwsh twn Ekpaideutikwn sth Xrhsh twn Newn Texnologiwn -To paradeigma twn Eentrwn Sthrhkshs Epimorfoshs: thewrhtikh kai empeirikh prosegish. Adelfoi Kyriakidh, Thessalonikh (2005)

17. Hartzoulakis, V.: Computer Assisted Language Learning (CALL) in the Greek Public Primary and Secondary Sector. Aspects today 17, 15-20 (2008)

18. Vassala, P., Motsios, G.: H eisagwgikh epimorfwsh twn ekpaideutikwn prwtovathmias ekpaideushs: Symvatika hex apostasews programmata. Ekpaideush Enhlikwn 11, 12-20 (2007)

19. Imel, S.: Transformative Learning in Adulthood. ERIC Digest No. 200 (1998), http: //www.ericdigests.org/1999-2/adulthood.htm (retrieved April 5, 2008) 
20. Survey: Good grade for online learning. Sacramento Business Journal (2005), http://sacramento.bizjournals.com/sacramento/stories/2005/ $06 / 13 /$ daily20.html (retrieved June 19, 2005)

21. Coventry, L. (n.d.): Video Conferencing in Higher Education, http://www.agocg.ac.uk/reports/mmedia/video3/contents.htm (retrieved July 31, 2005)

22. Ajayi-Dopemu, Y., Talabi, J.K.: The effects of videotape recording on microteaching training techniques for education students. Learning, Media and Technology 12(1) (January-March 1986),

http: / /www. informaworld. com/smpp/ content content=a746999670 $\mathrm{db}=\mathrm{all}$ order=page (retrieved April 23, 2008)

23. Kwstika, I.: H Epimorfwsh twn Ekpaideutikwn: Diereunhsh Apopsewn kai Stasewn twn Stelexwn Ekpaideushs. delfoi Kyriakidh, Thessalonikh (2004)

24. Nanjappa, A., Grant, M.: Constructing on Constructivism: The Role of Technology. Electronic Journal for the Integration of Technology in Education 2(1) (Spring 2003), http://ejite.isu.edu/volume2No1/nanjappa.pdf (retrieved April 6, 2008)

25. Microteaching (n.d.), http://www.answers.com/topic/microteaching (retrieved April 23, 2008)

26. Rowan, L.: Surfing Electronic Waves: The Application of Videoconference Technology in Tertiary Teaching (2000),

http://ultibase.rmit.edu.au/Articles/online/rowan1.htm (retrieved January 8, 2006)

27. Brookfield, S.: An Agenda for Research and Policy. National-Luis University (1995), National-Luis University, Web site,

http: / /www.nl .edu/academics/cas / ace/facultypapers / StephenBrookfield_Agenda.cfm (retrieved July 28, 2008)

28. European Council. Detailed work programme on the follow-up of the objectives of Education and training systems in Europe. Official Journal of the European Communities 142(01) (2002), Eur-lex Europa Web site,

http://eur-lex.europa.eu/pri/en/oj/dat/2002/c_142/

C_14220020614en00010022.pdf (retrieved April 24, 2008)

29. Education Council \& European Commission. Modernising Education and Training: A Vital Contribution to Prosperity and Social Cohesion in Europe. 2006 Joint Interim Report of the Council and of the Commission on Progress under the Education \& Training 2010 Work Programme. Official Journal of the European Union 79(1) (2006), Eur-lex Europa Web site, http: / / eur-lex.europa.eu/LexUriServ/LexUriServ.do? uri=OJ :C:2006:079:0001:0019:EN:PDF (retrieved April 24, 2008) 